\title{
Students' Views on AFAD (Disaster and Emergency Management Authority) Trip as an Outdoor Learning Environments in Teaching "Natural Disasters"
}

\author{
Asst. Prof. Görkem Avcı \\ Bartın University-Turkey \\ Prof.Dr. Nevzat Gümüş \\ Dokuz Eylul Unlversity-Turkey
}

\begin{abstract}
The topic of natural disasters is vital for the whole world to focus on. The purpose of this study is to explore the students' views on the field trip to AFAD (Disaster and Emergency Management Authority) as an outdoor learning environments in Primary School the 4th grade "Social Studies" course. One of the qualitative research designs, pheomenology, was used in this study. The study group consisted of 33 students in the 4th grade of a primary school at the middle socio-economic level in İzmir-Turkey in the 2018-2019 academic year. The semi-structured interviews were designed by the researchers and the content analysis was carried out on the interviews. In the semi-structured interviews, 4th graders maintained that they learned better from the first hand experiences involving many senses. They also indicated that they had such feelings of fun, joy, thrill, they got positive impressions overall and their curiosity and interest increased. Besides, experiential learning had a lasting impact on them. As a result, it has been determined through student opinions that it is necessary to focus on a vital issue such as natural disasters and that the educational trip organized is effective, beneficial and long lasting for students.
\end{abstract}

Keywords: experiential learning; out of school learning; outdoor education; outdoor learning; social studies. 